UJBM, Vol. 4, No. 1, January - June 2005, pp 1-7

ISSN 0975-3311 | https://doi.org/10.12725/ujbm.5.1

\title{
ORGANIZATIONAL PERFORMANCE: CONCERNS IN CONSTRUCT MEASUREMENT
}

Nandakumar Mekoth* \& N Barnabas**

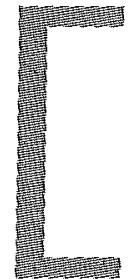

\section{Abstract}

There is no consensus among researchers on the definition and measurement practices of Organizational Performance. Some suggest that it is best left as a conceptually rather than empirically relevant construct.

\section{Measuring Organizational Performance}

\section{Introduction}

Many attempts to define and measure organizational performance drew uniformly negative conclusions about the concept. Steers (1975) commented that there is only a rudimentary understanding of what actually constitutes the concept of organizational effectiveness. Hrebiniac (1978) viewed the measuring of performance

*Department of Management Studies, Goo University, Goo

**Lecturer, Department of Commerce, Christ College, Bangalore 
as "a critical but problematic issue". Some researchers considered organizational performance as an "untidy concept" and even argued that the concept is not researchable, and should reside only as a conceptually rather than empirically relevant construct (Hannan and Freeman, 1977). However, there have been efforts - both postulations as well as empirical research - to define and measure organizational effectiveness. The objective of this article is to trace back to early deliberations, the issue of measuring organizational performance. It also aims at identifying the weaknesses and gaps in existing literature and giving logical directions for future research that contribute to the richness of the concept. Finally, the review gives a more elaborate coverage of the latest and most comprehensive measurement tool popularly accepted today; the Balanced Score Card.

Different schools of researchers adopted differing approaches to study and measure organizational performance. Organizational theory gives three fundamental theoretical approaches to measuring organizational effectiveness (Carvana, Ewing and Ramaseshan, 1998).

1. Goal based approach

2. Systems approach

3. Multiple constituency approach

\section{Goal based approach}

In the goal based approach organizational performance is evaluated on the basis of self imposed objectives (Etzioni, 1964). According to organizational goal theorists the issue of specifying performance/effectiveness criteria is largely one of goal setting. Here the goals refered to in the "official" goal statements such as those found in articles of incorporation, organizational chart and the life, are seen as naive. (Perrow 1961; Porter, Lawler and Hackman, 1976). But the empirical study of Vroom (1960) and Lawrence and Lorch (1967) suggested that a strong goal consensus, even among the senior management of the organization can not be assumed. However, they do not suggest any solutions if there exists as disagreement of goals among dominant stake holders.

\section{Systems approach}

Georgopolous and Tannenbaum (1957) improve up on the goal based approach in their systems approach. They viewed effectiveness within a system framework and concluded that the idea of effectiveness can be best understood in terms of productivity, flexibility, and in the absence of inter-organizational strain. At the most global level the propounders of functional analysis, Parson (1960) and Lyden (1975), 
argue that organizational performance can be assessed based on how well an organization solves the four essential problems: goal attainment, adaptation, integration and pattern maintenance. Yuchtman and Seashore (1967) also approves the systems approach to measure organizational performance. They considered that the three basic processes in an open system view of an organization - resource acquisition, transformation and disposal - are tightly interconnected. So they chose to measure effectiveness from the input acquisition angle and defined organizational effectiveness as the ability of the organization to exploit its environment in the acquisition of scarce and valued resources.

Steers (1975) classified research literature on performance measures into univariate methods and multivariate methods. Though he merited the multivariate methods, he criticised the lack of consensus among them and also the lack of overlap among the variables. He observed that a more flexible and comprehensive model is required. Steers suggested that this more flexible, contingent approach (contingent since they include dynamic variables) to measure organizational performance should allow for the explicit acknowledgement of certain constraints that necessarily obstruct criteria maximization. Such constraints can be found in the structure, technology, environment and membership of a given organization. He suggested a "weighted" goal optimization model where the criteria are weighted on their importance. Thus Steers, in his postulation, made an effort to bring in the multi-dimensionality of the criteria, their differences in the impact and their dynamic nature. However, beyond suggesting the possible characteristics of a better model, he did not suggest any specific model and nor did he support it with any empirical study. Thus, the systems approach took into consideration the multiple generic performance aspects in performance measurement. However, the approach was criticized for its lack of dynamism and insufficiencies by later researchers.

\section{Multiple Constituency Approach}

Connolly, Conlon and Deutch of Georgia Institute of Technology (1980), in their multiple constituency approach argued that the existing approaches to organizational effectiveness were conceptually conflicting and empirically arid. They commented that many researchers appeared handicapped by the desire to produce a single effectiveness statement about any given organization. Instead, the authors proposed the multiple constituency approach at avoid the requirement for a single measure, explicitly assuming that an organization's different constituencies will form different assessments of its effectiveness. Theirs was a view of effectiveness that allowed multiple evaluations from multiple constituencies. According to them the answer to the question "how well an organization is performing?" is contingent on to whom (i.e. the constituency) we are posing the question. They argued that individuals 
become involved with the organization for a variety of different reasons, and these reasons will be reflected in a variety of different evaluations.

\section{The Strategic Management School}

The strategic management school thinkers integrated the above three views and suggested multiple dimensions in terms of financial performance and operational performance.

\section{a) Financial performance}

Venkatraman and Vasudevan Ramanujam (1986) studied business performance as a subset of the overall concept called organizational performance. According to them the narrowest conception of business performance is to center around the use of simple outcome based financial indicators that are assumed to reflect the fulfillment of the economic goal of the firm. Typically, the Financial Measures approach would be to examine such indicators as sales growth, profitability (as reflected in ratios such as return on investment, return on sales, return on equity), earnings per share, etc.

\section{b) Operational performance}

A broader conceptualization of business performance includes an emphasis on the indicators of operational performance (non-financial) besides financial indicators. (Hofer and Sanberg, 1987; Kaplan, 1983; Venkataraman and Vasudevan Ramanujam 1986). Measures logically included in operational performance were market share, new product introduction, product quality, marketing effectiveness, manufacturing value added and other measures of technological efficiency within the domain of business performance.

Though the strategic management school - motivated by the belief that systematic approaches to measurement approaches are likely to lead to superior operationalizations - classified and highlighted the advantages and limitations of different measurement approaches, a long debate on which measure is more relevant - whether financial or operational - still prevailed.

\section{Balanced Score Card}

In 1992 Kaplan and Norton introduced the measurement tool called Balanced Score Card (BSC). They argued that traditional financial performance measures suited the industrial era but were out of step with the skills and competencies that 
companies are trying to master foday. Interestingly, financial measures tell us of results of actions already taken and not of what would happen. According to them no single measure can provide a clear performance target or focus attention on all the critical areas of business. Therefore, there is a need for the balanced presentation of both financial and operational measures. The BSC complements financial measures with operational measures on customer satisfaction, internal processes and the organization's innovations and improvement activities, thus providing a more holistic approach to organizational performance measurement.

$\mathrm{BSC}$ is a performance measurement and strategic management system that translates an organization's mission and strategy into a balanced set of integrated performance measures. Performance measures provide a concise yet complete picture of an organization's progress toward its mission and goal. Organizations that have adopted BSC have reported varying degrees of success with its use as a motivational tool and as a form of performance feedback.

BSC's strength lies in its use of both financial and non-financial measures in encouraging and rewarding employees in achieving an organization's long-term goals. Kaplan and Norton argue that, in the information age, organizations require new capabilities for competitive success, such as customer relationships, product innovation, customized products, employee skills, motivation and information technology. By including all critical success factors in the performance measurement system, the organization will have a better idea of how to achieve its goals.

BSC complements the traditional financial perspective with other non-financial perspectives, such as customer satisfaction, internal business process, learning and growth. It also mixes outcome measures (the lagging indicator) with performance drivers (the leading indicator) because, according to Kaplan and Norton, "outcome measures without performance drivers do not communicate how the outcomes are to be achieved." By selecting the appropriate performance drivers and outcome measures, the organization will have a better idea of its potential competitive advantage.

The balanced set of performance measures tells a concise yet complete story about the achievement and performance of the organization toward its goals and provides a holistic view of what is happening in the organization. By tying these performance measures to rewards, BSC ensures that the employees will do what is best for the organization as a whole. 
Companies can use BSC to accomplish the following objectives:

- Clarify a consensus strategy

- Communicate strategy throughout the organization

- Align departmental and personal goals to the strategy

- Link strategic objectives to long-term targets and annual budgets

- Identify and align strategic initiatives

- Perform periodic and systematic strategic reviews

- Obtain feedback to improve strategy

Applying BSC generally begins with an articulation of corporate strategy by the top management, followed by a rough sequence of implementation steps:

- Devising the measure: List the measures that gauge the most critical factors of success.

- Pinning down causal linkages: Choose measures that fit in a chain of causeand-effect relationships to come up with a concrete logic for creating value.

- Cascading the scorecards: Once top managers have devised a scorecard for the organization as a whole, the next job is to devise complementary scorecards for each unit.

- Linking to compensation: Pay employees for achieving goals by linking BSC measures to pay.

- Preparing the information technology infrastructure: Prepare the information. Organize data gathering and reporting to match the logic of the BSC.

- Prepare the technology. Configure and manage the components of systems appropriate to creating an integrated system.

- Obtaining and using feedback: Conduct periodic meetings and evaluations to provide feedback and support continuous improvement.

However, an empirical study conducted by Kathy and McKay found that BSC may not be a universally applicable measure. At an automobile manufacturer, BSC successfully integrated organizational goals into the daily activities of the employees. However, in the second case, a bank replaced BSC with an alternative measuring approach because the bank found BSC inappropriate for the organizational culture it wanted to create. The researchers cited that organizations experienced such different results and levels of satisfaction due to the differences in the efficiency of the internal feedback system of the organization. 


\section{Conclusion}

The concept of organizational performance has been very extensively studied. However, few researchers have agreed upon any single definition of the concept. As a result efforts to measure the concept empirically have also been varied. The balanced score card provides a more comprehensive measurement but has not proved effective in all contexts. Moreover, most measurements of organizational performance are subjective. Therefore, even if a more comprehensive measure is developed, the issue of objective measurement of the concept will still remain unaddressed.

\section{References:}

- Caruana, A., Ewing and Ramaseshan, N. "Do universities that are market oriented perform better?" International Journal of Public Sector Management, April 1999

- Connolly T, Conlon E J, and Deutch S J, "Organizational Effectiveness - A Multiple Constituency Approach" Academy of Management Review, 1980, Vol. 5, No. 2, 211 -217.

- Etzioni, Modern Organizations, Prentice Hall, 1964, Eaglewood Cliffs, 1964.

- Georgopolous, B. S and Tannenbaum, A. S. "The Study of Organizational Effectiveness" American Sociological Review, 1957, 22: 534-540

- Hannan, M T. and Freeman, J. "The population ecology of organizations" American Journal of Sociology, 1977, 82, 929-964.

- Hrebiniak, L G. Complex Organizations, New York: West Publishing Company, 1978.

- Kaplan, R S and Norton, D P. "The Balanced Score Card" Harvard Business Review, Jan/Feb 1992, Vol 70, issue 1.

- Kathy, S J and McKay, R B. "Balanced Score Card: Two Perspectives", The CPA Journal, March 2002, p 21-25.

- Lawrence, P. R. and Lorch, J. W. "Differentiation and integration in complex organizations", Administrative Science Quarderly, 1967, 12, 1-47.

- Lyden, F J. "Using Parson's functional analysis in the study of public organizations". Administrative Science Quarterly, 1975, 20, 59-70.

- Steers, M.R. "Problems in the measurement of organizational effectiveness" Administrative Science Quarterly, 1975, Vol. 20, 546-558.

- Venkatraman, $N$ and Ramanujam, V, "Measurement of Business performance in strategy Research" Academy of Management Review, 1986, Vol 1, No. 4, 801-814.

- Vroom VH. "The effects of attitudes on perceptions of organizational goals" Human Relations, 1960, 13, 229-240.

- Yuchtman, E and Seashore, E Stanley. "Factorial analysis of organizational performance" Administrative Science Quarterly, 1967. 